\title{
Chylothorax in infancy
}

\author{
W O J C I E C H J E S K E \\ From the Department of Paediatrics, Staincliffe General Hospital, Dewsbury, Yorkshire
}

A case of chylothorax in an infant is presented. Treatment with continuous drainage and suction was successful.

Chylothorax was probably first described by Aseli in 1677 (cited by Kirkland, 1965). It can occur neonatally and during infancy, in childhood, and in adult life. In the neonatal period less than 20 cases had been recorded up to 1965 (Kirkland, 1965). These were considered to be due to a congenital defect in the thoracic duct, and in a few to birth trauma, convulsions, or respiratory obstruction. In childhood and adult life, trauma including thoracic operations and extensor injuries of the spine are the usual causes. Less common are neoplasms and inflammatory obstruction. Spontaneous chylothorax in infancy and childhood is rare; only four cases have been reported up to 1965 (Kirkland. 1965).

\section{CASE REPORT}

C. L. M. had a normal birth weight of $7 \mathrm{lb} .9 \mathrm{oz}$. $(3.4 \mathrm{~kg}$.). She was cyanosed after birth and examination of the chest showed increased dullness over the left base. A diagnosis of partial atelectasis was made but this cleared up in the next few days.

She was then well until $7 \frac{1}{2}$ months of age, when she developed a cough and shortness of breath. On the third day of the illness this became more severe and she was admitted to hospital on 6 January 1967. At this time she was in moderate respiratory distress with a temperature of $100^{\circ} \mathrm{F}$. and a respiration rate of 80 per minute. Respiratory movements of the left chest were diminished. On percussion, dullness was found over the left chest and auscultation revealed absent air entry and diminished vocal resonance. She had a few scattered crepitations over the right lung field. A radiograph of the chest revealed a diffuse left-sided opacity (Fig. 1), and a pleural effusion was diagnosed.

The chest was aspirated, and $210 \mathrm{ml}$. of slightly haemorrhagic milky fluid were withdrawn. Further aspiration of $75 \mathrm{ml}$. was performed the following day. A subsequent radiograph (Fig. 2) revealed a hydro-

'Present address: I Clinic of Internal Medicine, Institute of Postgraduate Medical Education, Bielany, Warsaw, Poland pneumothorax. As she became more dyspnoeic continuous suction and drainage by an axillary intercostal $\vec{A}$ polyethylene tube was instituted. During the next 36 o hours $820 \mathrm{ml}$. of liquid were drained. Following this the liquid markedly diminished in amount and in the next 10 days only $460 \mathrm{ml}$. were drained. By this time the lung was fully expanded. The tube was withdrawn after 14 days.

She was discharged symptom free after 28 days in hospital. The lung was fully expanded with only a small amount of residual opacity. A follow-up radiograph four weeks later showed a normal chest.

Supportive therapy was given during the first few days. This consisted of blood, intravenous plasma, and saline. Antibiotic cover was also given with ampicillin and cloxacillin.

The fluid analysis contained protein, $4.7 \mathrm{~g} . / 100 \mathrm{ml}$. ; sugar, $140 \mathrm{mg} . / 100 \mathrm{ml}$; cholesterol, $80 \mathrm{mg}$. ; fat (as fatty acids), $1.3 \mathrm{~g} . / 100 \mathrm{ml}$. The fluid was bacteriologically sterile. The haemoglobin remained about $80 \%(11.7 \mathrm{~g} . / 100 \mathrm{ml}$.). The W.B.C. on admission was $10,000 /$ c.mm., with 80 neutrophils. A further W.B.C. three days later was 3,500/c.mm., with $68 \%$ of neutrophils, and the last W.B.C. two weeks later was ? 4,500/c.mm. (neutrophils 29\%, eosinophils $13 \%$, 윽 lymphocytes $42 \%$, and monocytes $16 \%$ ). The serum 3 . protein was $5 \mathrm{~g} . / 100 \mathrm{ml}$. on the third day and a $\delta$ further estimation of the serum protein showed $5.7 \gtreqless$ g./100 $\mathrm{ml}$. before discharge.

\section{DISCUSSION}

As the thoracic duct ascends mainly in the right $N$ side of the mediastinum and only inclines to the left at the level of the fifth thoracic vertebra, 0 leakage of the duct into the pleura must have taken place high in the pleural cavity. Possibly $\frac{\circ}{\Phi}$ there was a defect in communication between the $\stackrel{0}{\rightarrow}$ thoracic duct and the left bronchomediastinal 0 lymph trunk. Trauma, which may be very slight, $\vec{\circ}$ could then have started the leakage into the pleural $\mathbb{D}$ cavity. It seems that in all cases of spontaneous $\frac{\mathbb{D}}{\mathbb{D}}$ chylothorax and in those where mild trauma is $\frac{\varrho}{\sigma}$ considered to be causal (e.g., cough, convulsions, 


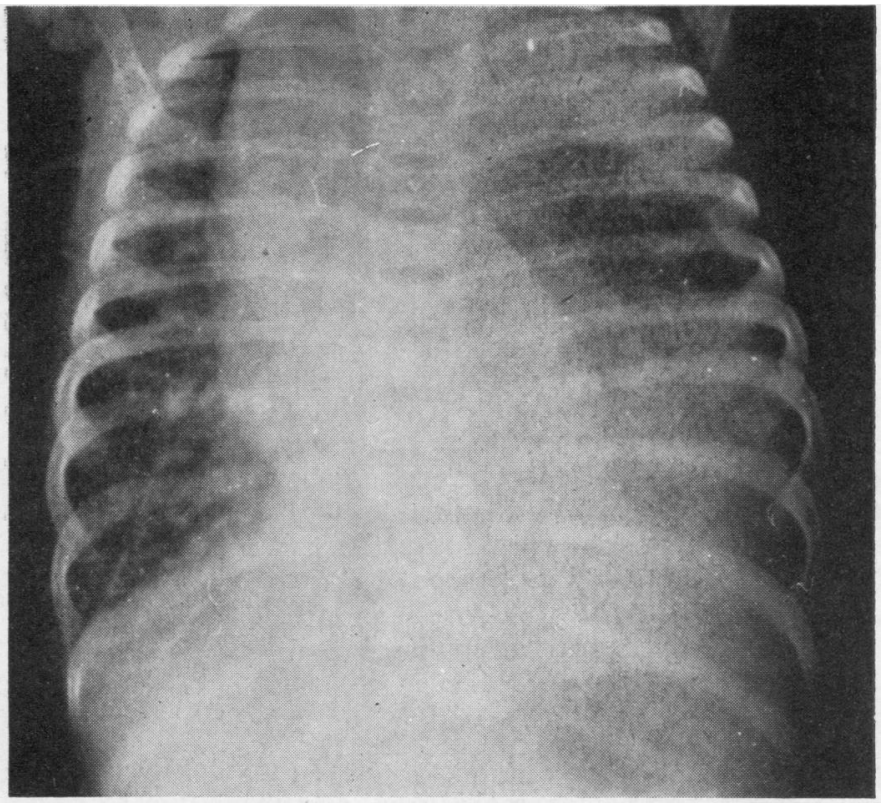

FIG. 1. Radiograph of chest on admission. blood are important additional measures.

Thoracotomy with closure of points of leakage and ligation of the proximal duct is reserved for patients who have continuing large losses of chyle and in whom the prospect of nutritional deficiency is imminent. In some cases lymphangiography immediately after aspiration may help to localize the site of leakage.

I am indebted to Dr. C. S. Livingstone, consultant paediatrician, under whose care the child was admitted. for his help and permission to publish this case.

\section{REFERENCES}

Decancq, H. G., Jr. (1965). The treatment of chylothorax in children. Surg. Gynec. Obstet. 121, 509.

Kirkland, I. (1965). Chylothorax in infancy and childhood. A method of treatment. Arch. Dis. Childh., 40, 186.

:and spinal hyperextension) some underlying abnormality of the lymphatic system must predispose to the development of this condition.

MANAGEMENT Cross in 1882 may have had the solution when he said, 'the pleura must be continuously and thoroughly drained until such a time as the visceral and parietal pleurae come in contact'. In the literature, different ways of management have been advised, and it has been recognized recently that therapy should be conservative, with continuous drainage and negative pressure. A statistical review, presented by Decancq in 1965 , showed that with this treatment amounts of aspirated fluid were smaller and cure was obtained most quickly.

Supportive therapy in each individual case is of importance and should consist of a high protein diet with split fats, vitamin supplement, and antibiotic cover. Transfusion of albumin, plasma, or

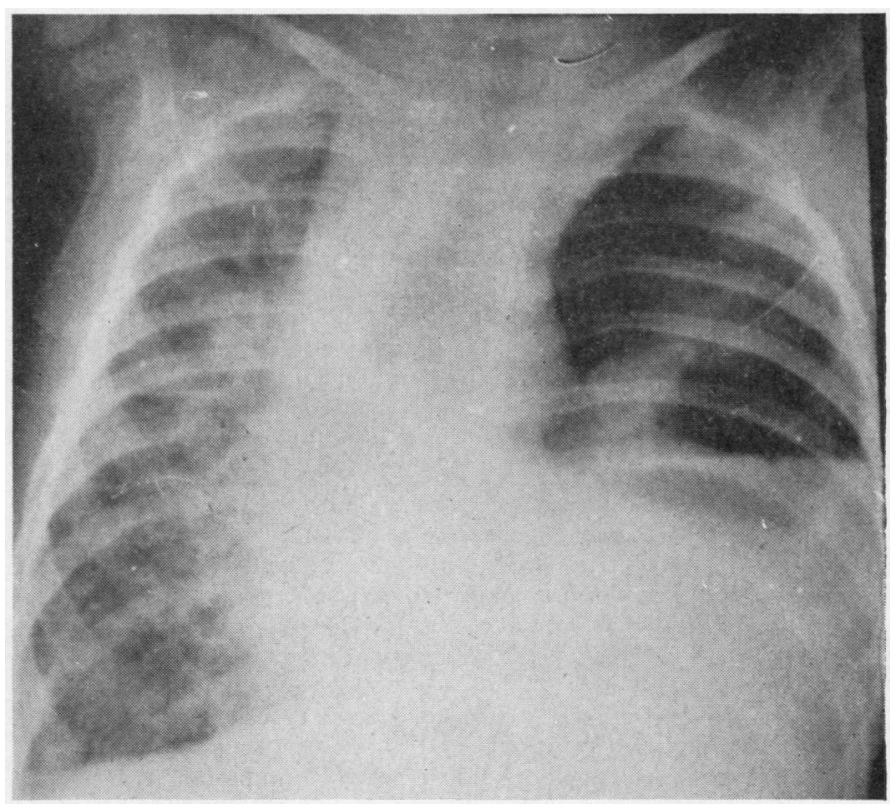

FIG. 2. Chest radiograph after the second aspiration which was complicated by a hydropneumothorax. 